\title{
Cyclam-based compounds as a novel class of antibacterial and antitumoral agents
}

\author{
Luis G. Alves, ${ }^{1}$ Adhan Pilon, ${ }^{2,3}$ Sergi Rodriguez-Calado, ${ }^{4}$ João F. Portel, ${ }^{2,5}$ Olga Ferreira, ${ }^{6}$ Sílvia A. Sousa, ${ }^{5}$ Andreia Valente, ${ }^{3}$ Julia \\ Lorenzo, ${ }^{4}$ Elisabete R. Silva, ${ }^{6}$ Ana M. Martins, ${ }^{2}$ Jorge H. Leitão $^{5}$ \\ ${ }^{1}$ CQE - Associação do Instituto Superior Técnico para a Investigação e Desenvolvimento, Av. Rovisco Pais 1, 1049-003 Lisboa, Portugal \\ ${ }_{2}^{2}$ CQE - Instituto Superior Técnico, Universidade de Lisboa, Av. Rovisco Pais 1, 1049-001 Lisboa, Portugal \\ ${ }^{3}$ CQE - Faculdade de Ciências da Universidade de Lisboa, Campo Grande, 1749-016 Lisboa, Portugal \\ ${ }^{4}$ Institut de Biotecnologia i de Biomedicina, Universitat Autònoma de Barcelona, 08193 Bellaterra, Barcelona, Spain \\ iBB - Instituto Superior Técnico, Universidade de Lisboa, Av. Rovisco Pais 1, 1049-001 Lisboa, Portugal \\ BiolSI - Faculdade de Ciências, Universidade de Lisboa, Campo Grande, 1749-016 Lisboa, Portugal
}

\section{INTRODUCTION}

Cyclams are macrocyclic polyamines which medical interest was fueled by the therapeutic potential of a bicyclam derivative in HIV infection, inflammatory diseases, cancer and stem-cell mobilization. [1] Taking advantage of the biocompatibility, the high metal chelation stability constants and the possibility of $\mathrm{N}$-functionalization of the cyclam backbone, a variety of compounds have been explored in a wide range of medicinal applications. [2] The use of cyclams and cyclam-based complexes as antimicrobial and antitumoral agents has been recently described. [3-5]

\section{RESULTS AND DISCUSSION}

\section{Antibacterial Activity}

Reactions of transdisubstituted cyclams of general formula $\mathrm{H}_{2} \mathrm{Bn}_{2}$ Cyclam, 1-5, with Brønsted acids led to the formation of the corresponding salts 16 as shown in Scheme 1. Depending on the $\mathrm{pK}_{\mathrm{a}}$ of the acid used, dicationic (6-10) or tetracationic (1116) salts are obtained.
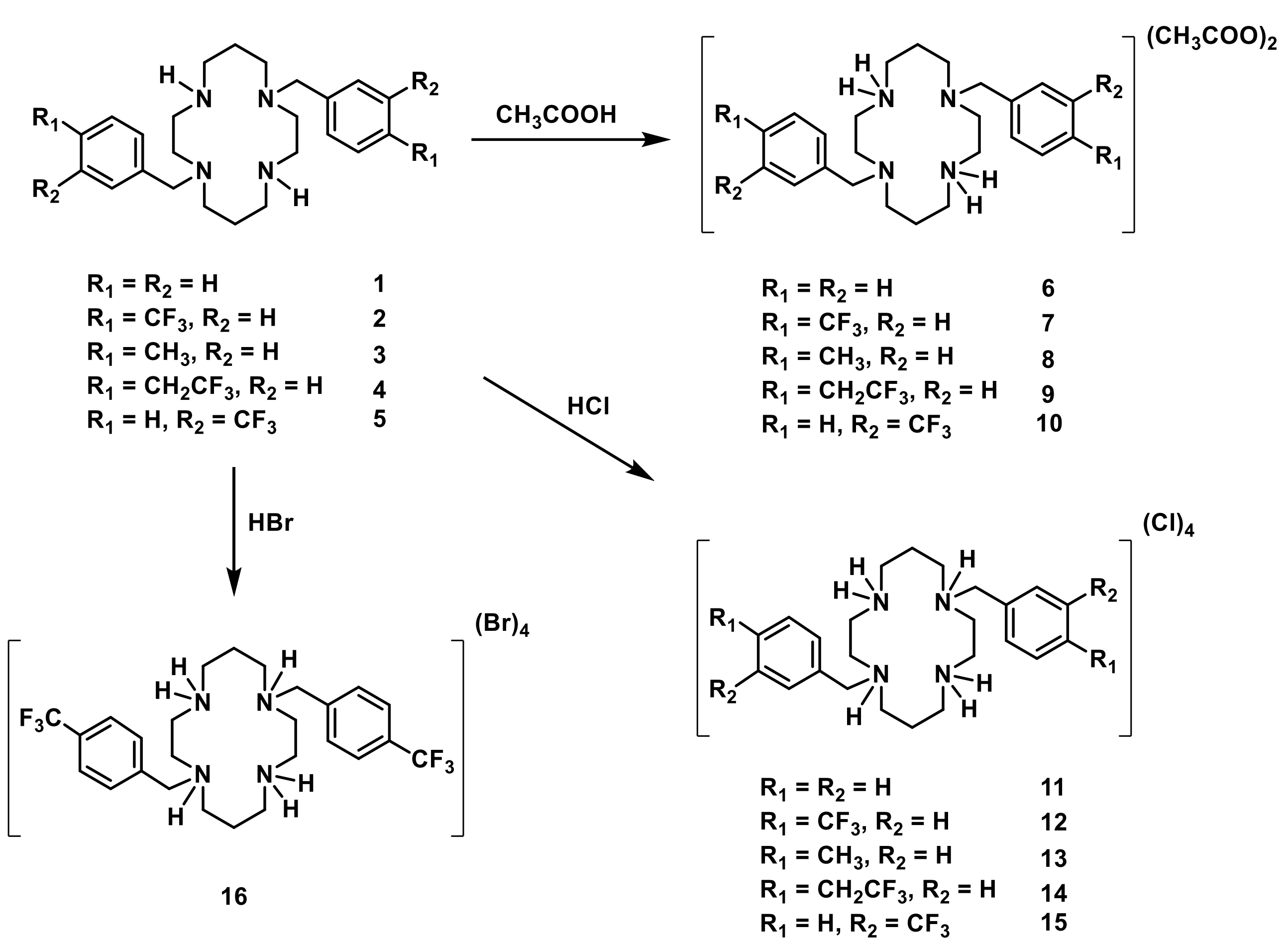

Scheme 1

The Minimal Inhibitory Concentration (MIC) values determined for compounds 6-16 to $S$. aureus and E. coli species are presented in Figure 1. The structure/activity relationship reveals that the presence of a $\mathrm{CF}_{3}$ group on the aromatic ring of the cyclam pendant arms is crucial for the antibacterial activity of the compounds.

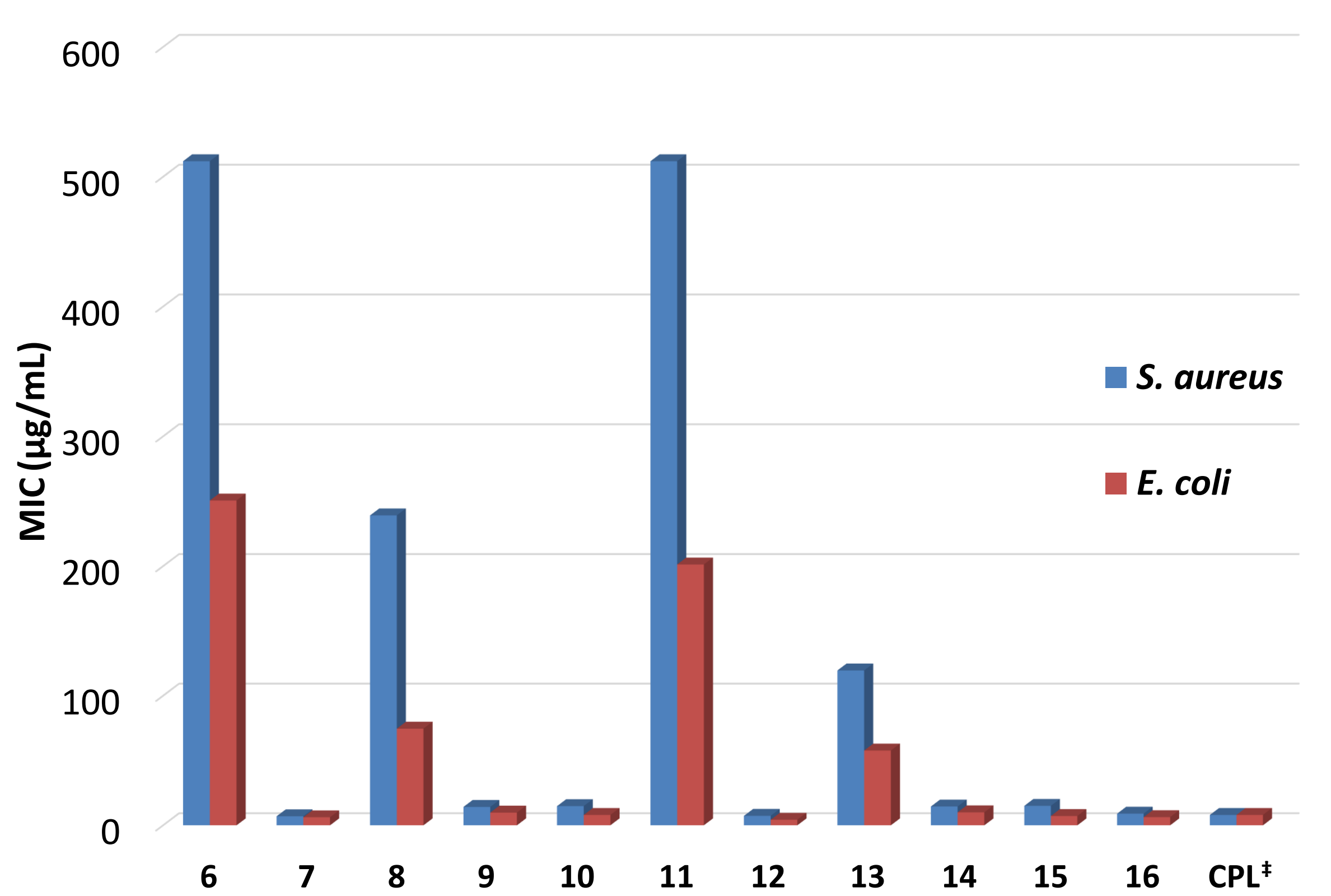

Figure 1. MIC values $(\mu \mathrm{g} / \mathrm{mL})$ for 6-16 and chloramphenicol $(\mathrm{CPL})^{\ddagger}$ determined for S. aureus Newman and E. coli ATCC25922 in MHB liquid media.

‡Data obtained from EUCAST

\section{Antitumoral Activity}

Cyclam derivatives 17 and 18 react with one equiv. of $\mathrm{Cu}\left(\mathrm{CH}_{3} \mathrm{COO}\right)_{2} \cdot \mathrm{H}_{2} \mathrm{O}$ to afford complexes of formula $\left[\mathrm{Cu}\left\{\left(\mathrm{HOCH}_{2} \mathrm{CH}_{2} \mathrm{CH}_{2}\right)_{2} \mathrm{Bn}_{2} \mathrm{Cyclam}\right\}\left(\mathrm{CH}_{3} \mathrm{COO}\right)\right]\left(\mathrm{CH}_{3} \mathrm{COO}\right)$, where $\mathrm{Bn}=\mathrm{PhCH}_{2}, 19$,

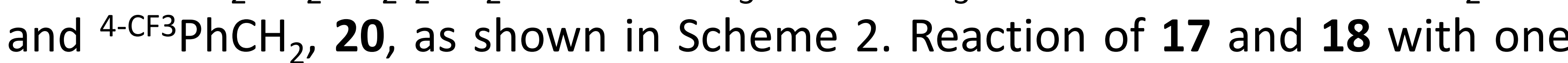
equiv. of $\mathrm{FeCl}_{3}$ led to the formation of the corresponding $\mathrm{Fe}(\mathrm{III})$ complexes 21 and 22 (see Scheme 2).
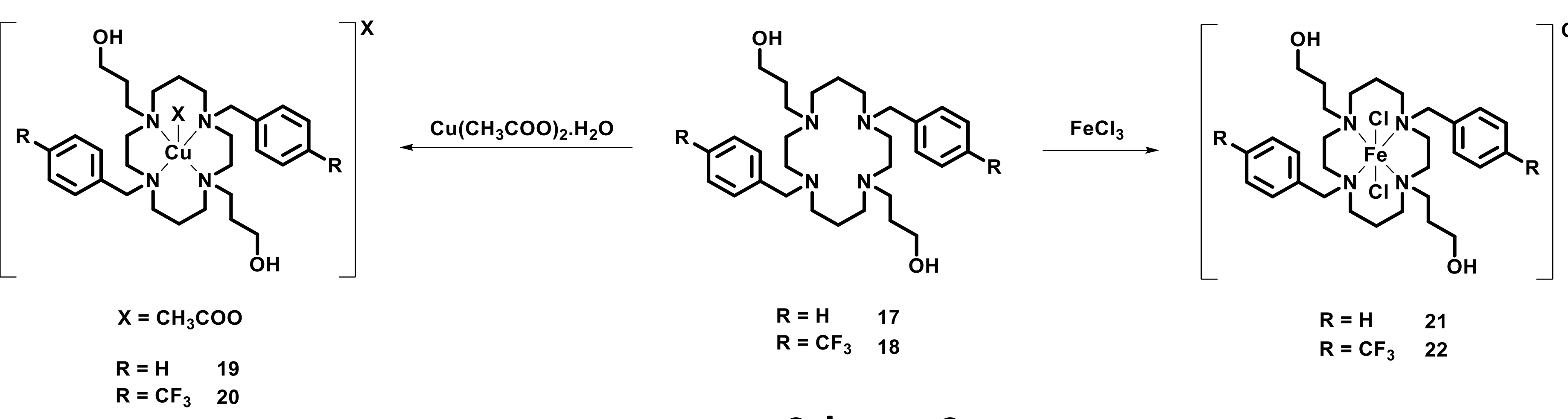

Scheme 2

The $\mathrm{IC}_{50}$ values of 17-22 obtained for the growth inhibition of HeLa cells are presented in Figure 2. At $24 \mathrm{~h}$ incubation only compound $\mathbf{1 8}$ and complexes $\mathbf{2 0}$ and $\mathbf{2 2}$ are cytotoxic, while at $72 \mathrm{~h}$ incubation all the compounds show significant antiproliferative effects. Notably, compounds displaying $p-\mathrm{CF}_{3}$ on the aromatic rings of the macrocyclic pendant arms as well as their $\mathrm{Cu}$ (II) and Fe(III) complexes are up to 12 times more cytotoxic than cisplatin at $24 \mathrm{~h}$ incubation.

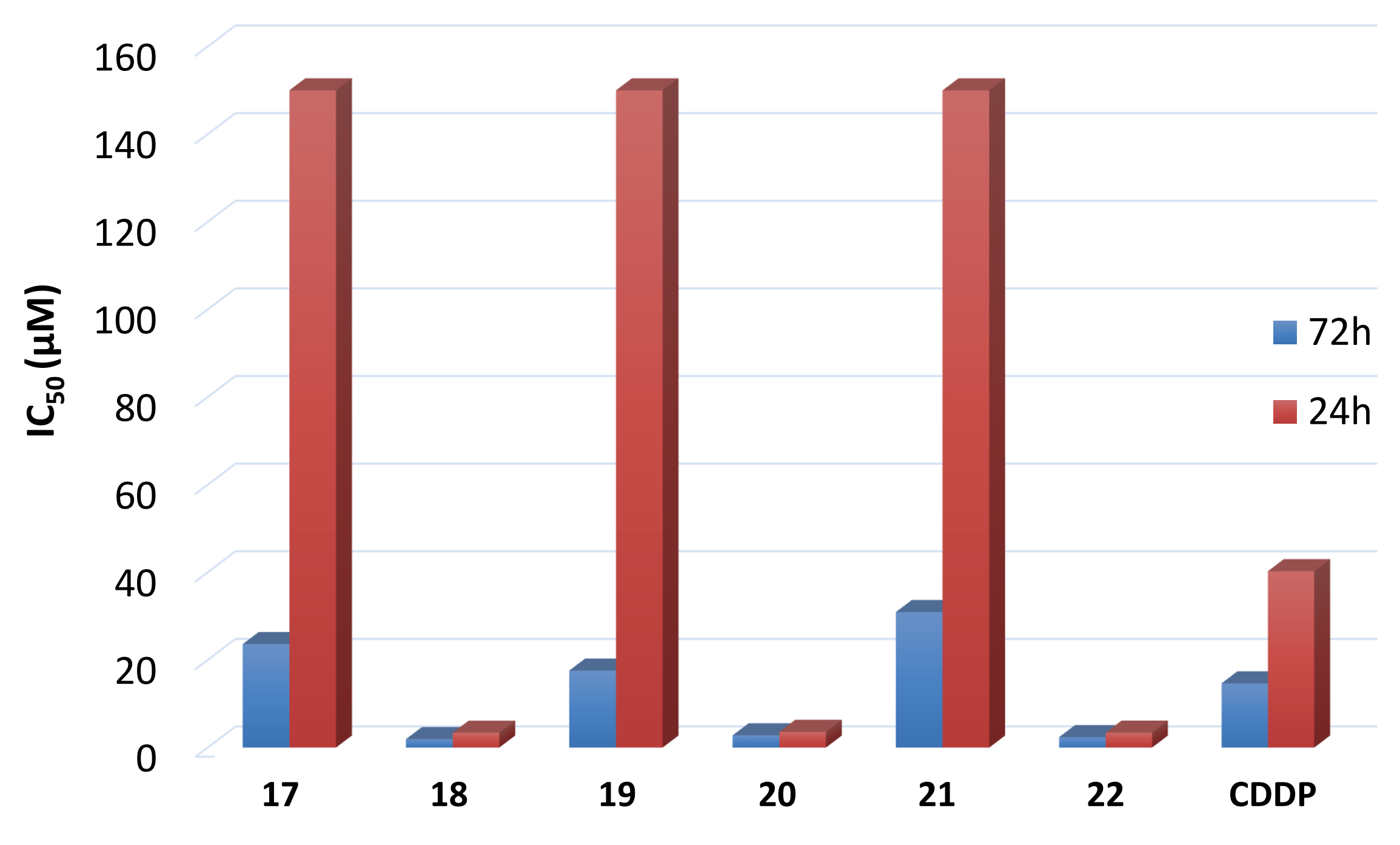

Figure 2. $I C_{50}$ values ( $\left.\mu \mathrm{M}\right)$ for compounds 17-22 and cisplatin (CDDP) in HeLa cells.

\section{CONCLUSIONS}

The antibacterial and antitumoral activity of cyclams reveals a strong dependence on the presence of the $\mathrm{CF}_{3}$ group on the aromatic ring of the macrocyclic pendant arms. Remarkably, these compounds display similar antibacterial activity as the commercial available antibiotic chloramphenicol and are up to 12 times better than cisplatin for HeLa cancer cells. As far as we are aware, compounds of formula $\left[\left\{\left(\mathrm{HOCH}_{2} \mathrm{CH}_{2} \mathrm{CH}_{2}\right)_{2} \mathrm{Bn}{ }_{2} \mathrm{Cyclam}\right\} \mathrm{FeCl}{ }_{2}\right] \mathrm{Cl}$, are the first Fe-Cyclam compounds to be ever tested as anticancer agents.

\section{REFERENCES}

[1] De Clercq, E. Nat. Rev. Drug Discov. 2003, 2, 581-587

[2] Liang, X. et. al. Chem. Soc. Rev. 2004, 33, 246-266

[3] Yu, M. et. al. J. Med. Chem. 2016, 59, 5917-5921

[4] Alves, L. G. et. al. Int. J. Antimicrob. Agents 2017, 49, 646-649

[5] Pilon, A. et. al. ChemMedChem 2019, 14, 770-778

\section{AKNOWLEDGEMENTS}

This work was supported by the Fundação para a Ciência e Tecnologia, Portugal (projects UI/QUI/0100/2019 and UID/BIO/04565/2019) and by the Spanish Ministry of Economy, Industry and Competitiveness (project BIO2016-78057-R). Programa Operacional Regional de Lisboa 2020 (Project N.007317) is acknowledged for funding iBB. 